\title{
Laryngeal Cancer cM1 TNM Finding v8
}

National Cancer Institute

\section{Source}

National Cancer Institute. Laryngeal Cancer CM1 TNM Finding v8. NCI Thesaurus. Code C133152.

Laryngeal cancer with distant metastasis. (from AJCC 8th Ed.) 